\title{
Synergetic Effect between Phenolic Extracts of Ammi visnaga and Zea mays Formulation on the Corrosion of Mild Steel in $1 \mathrm{M}$ HCl Solution
}

\author{
Sarra Aourabi (D, Majid Driouch, Mariya Kadiri, Noura Achnine, Mouhcine Sfaira, \\ and Fatima Mahjoubi
}

Laboratory of Engineering, Modeling and Systems Analysis (LIMAS), University Sidi Mohamed Ben Abdellah (USMBA), Faculty of Sciences, P.O. Box 1796-30000, Fez-Atlas, Morocco

Correspondence should be addressed to Sarra Aourabi; sarra.aourabi1@gmail.com

Received 23 February 2021; Accepted 30 April 2021; Published 21 May 2021

Academic Editor: Liviu Mitu

Copyright (C) 2021 Sarra Aourabi et al. This is an open access article distributed under the Creative Commons Attribution License, which permits unrestricted use, distribution, and reproduction in any medium, provided the original work is properly cited.

\begin{abstract}
The synergetic effects between hydroethanolic extracts of A. visnaga $\mathrm{HE}(\mathrm{AV})$ and Z. mays hairs $\mathrm{HE}$ (ZM) on corrosion of mild steel in $1 \mathrm{M} \mathrm{HCl}$ solution was investigated at $298 \mathrm{~K}$ by two techniques: potentiodynamic polarization (PP) methods (Tafel and Stern \& Geary) and electrochemical impedance spectroscopy (EIS). The mixture of HE (AV)/HE (ZM) acted as an efficient corrosion inhibitor and its inhibition efficiency increased with concentration up to $96.55 \%$ at $0.01 \mathrm{gL}^{-1} \mathrm{HE}(\mathrm{AV}) / 0.2 \mathrm{gL}-\mathrm{HE}^{-1}$ (ZM). The polarization curves revealed that the mixture acted as a mixed-type inhibitor, with anodic predominant action. The EIS studies were fitted by the $\left(R_{s}+\mathrm{CPE}_{d l}\right) /\left(R_{c t}+\mathrm{CPE}_{f} / R_{f}\right)$ equivalent circuit model. The kinetic parameters were in favor of a physisorption character of adsorption of $\mathrm{HE}(\mathrm{AV}) / \mathrm{HE}(\mathrm{ZM})$ components onto the mild steel surface. The influence of exposure time on the efficiency of mixture extract was investigated. Scanning electron microscopy (SEM/EDX) analyses confirmed the formation of a protective adsorbed film upon the mild steel surface.
\end{abstract}

\section{Introduction}

Corrosion of metals causes huge economic losses of billions of dollars every year in several industries around the world [1]. One of the most practical and economical methods to protect industrial equipment from corrosion is the application of corrosion inhibitors [2]. Unfortunately, most of these corrosion inhibitors can present a high risk to the environment and humans [3-6]. However, plant extracts have become a more important corrosion inhibitor due to their low toxicity, high availability, and simple preparation [5]. According to the literature [7], most recent contributions are those using plant extracts to inhibit corrosion of steel in acid solutions, for example, Ammi visnaga extract [8-10], corn silk [11], and a mixture of Hevea brasiliensis (rubber) and leaf of Zea mays (corn cob) [12]. It is clear from these studies that the inhibitory properties of plant extracts are generally attributed to their variety and complex organic substances [13]. Recently, we presented electrochemical experimental evidence demonstrating that the hydroethanolic extract of Ammi visnaga [10] and the hydroethanolic extract of Zea mays hairs acted as a good corrosion inhibitor on mild steel in $1 \mathrm{M} \mathrm{HCl}$ solution [14]. PP studies have shown that $\mathrm{HE}(\mathrm{AV})$ functions as a mixed-type inhibitor and HE (ZM) acted as a mixed-type inhibitor with anodic predominant action in the hydrochloric acid system. Integrated EIS measurements with Nyquist diagrams revealed that $\mathrm{HE}(\mathrm{AV})$ and $\mathrm{HE}(\mathrm{ZM})$ have increasing corrosion inhibition efficiency with rise of concentration. In recent years, there has been great need to improve the inhibitory effect of green inhibitors and therefore reduce the cost of economic loss; eventual synergism can be considered as an effective way to improve the inhibiting efficiency of extracts.

In this work, we provide an extension of an earlier study on the synergistic inhibition effect between $\mathrm{HE} \mathrm{(AV)} \mathrm{and} \mathrm{HE}$ (ZM) on corrosion of mild steel in $1 \mathrm{M} \mathrm{HCl}$ solution by electrochemical techniques. The thermodynamic parameter 
allows determining the type of adsorption on metal surface. Scanning electron microscope (SEM) was used to exemplify the surface morphology of mild steel with and without inhibition intervention, in order to obtain more information on the corrosion inhibition effect of $\mathrm{HE}(\mathrm{AV}) / \mathrm{HE}(\mathrm{ZM})$ on mild steel in a $1 \mathrm{M} \mathrm{HCl}$ solution.

\section{Materials and Methods}

2.1. Vegetal Material. Ammi visnaga (A. visnaga) and Zea mays ( $Z$. mays) hairs were collected at the fruiting time in July 2019 in the Province of Taounate. The areal part was dried in the shade in a dry place and then crushed for later use. Samples were deposited at the herbarium of the Laboratory of Biotechnology and Preservation of Natural Resources of the Faculty of Sciences Dhar El Mahraz, University Sidi Mohamed Ben Abdellah, Fez, Morocco.

2.2. Material. The mild steel samples (containing $0.11 w t . \%$ C, 0.24 wt.\% Si, 0.47 wt.\% Mn, 0.12 wt.\% Cr, 0.02 wt.\% Mo, 0.10 wt.\% Ni, 0.03 wt.\% Al, 0.14 wt.\% Cu, 0.06 wt.\% W, Co $<0.0012$ wt.\%, $V<0.003$ wt.\%, and bal. Fe) were obtained by the conventional method widely reported in the literature [15]. The aggressive solution of $1 \mathrm{M} \mathrm{HCl}$ was prepared by dilution of analytical grade $37 \% \mathrm{HCl}$ with bidistilled water. The different concentrations of a mixture of $\mathrm{HE}(\mathrm{AV}) / \mathrm{HE}$ (ZM) were prepared with $1 \mathrm{M} \mathrm{HCl}$ addition.

\section{Methods}

3.1. Preparation of Phenolic Extracts. Phenolic extracts of $A$. visnaga and $Z$. mays hairs were obtained by ultrasounds with $45 \mathrm{~Hz}, 50 \mathrm{~W}$, and $308 \mathrm{~K}$, mixing the dry powder with ethanol/water $(70: 30)$ for $45 \mathrm{~min}$. The extracts were filtered and concentrated under reduced pressure.

3.2. Electrochemical Measurements. The electrochemical measurements were performed using a conventional threeelectrode glass cell with a thermostat double wall conducted by potentiostat/galvanostat (SP-150) and controlled with analysis software (Ec-Lab V11.20). The mild steel specimen was used as working electrode $(\mathrm{Ag} / \mathrm{AgCl}, 3 \mathrm{M} \mathrm{KCl})$ as reference electrode and platinum as auxiliary electrode. The polarization curves acquired from potentiodynamic polarization experiments were recorded in the potential range $\pm 250 \mathrm{mV}$ of open-circuit potential $E_{\text {ocp }}$, with a scan rate of $1 \mathrm{mV} \mathrm{s}^{-1}$. The corrosion parameters such as cathodic Tafel slope $\beta_{c}$, corrosion current density $i_{\text {corr }}$, and corrosion potential $E_{\text {corr }}$ were extracted by extrapolation from cathodic Tafel linear segment and were evaluated by Ec-Lab V11.20 software. The (S\&G) method, based on the determination of the polarization resistance $R_{p}$ of mild steel in the test solutions, was applied by exploiting the linear plot in the potential range of $\pm 25 \mathrm{mV}$, around $E_{\text {corr }}$. The impedance experiments were realized using a transfer function analyzer (Ec-Lab V11.20) in the frequency range domain from $10^{5}$ to $10^{-1} \mathrm{~Hz}$, with small perturbation amplitude of $10 \mathrm{mV}$ peak to peak, at $E_{\text {ocp. }}$. Before polarization and EIS measurements, the working electrode was left, in the test solution, during $30 \mathrm{~min}$ at $E_{\text {ocp }}$ potential. The impedance spectra were analyzed according to an appropriate equivalent circuit.

\subsection{Analyzing the Surface Using a Scanning Electron} Microscope. The surface morphologies of the samples were examined with a scanning electron microscope (SEM model FEI Quanta ${ }^{\circledR} 250$ ) equipped with EDX probe microanalysis of surfaces. The micrographs were taken after immersion of the samples in the corrosive solution for $24 \mathrm{~h}$, with and without $0.01 \mathrm{gL}^{-1} \mathrm{HE}(\mathrm{AV})+0.2 \mathrm{gL}^{-1} \mathrm{HE}(\mathrm{ZM})$.

\section{Results and Discussion}

\subsection{Electrochemical Behavior of Mild Steel in the Presence of Mixture $H E(A V)+H E(Z M)$ Extracts}

4.1.1. Potentiodynamic Polarization Measurements (PP). At $298 \mathrm{~K}$, the PP curves of mild steel in $1 \mathrm{M} \mathrm{HCl}$ in the presence and absence of different concentrations of $\mathrm{HE}$ $(\mathrm{AV})+\mathrm{HE}(\mathrm{ZM})$ are shown in Figure 1. We have taken the best concentration of $\mathrm{HE}(\mathrm{AV})$ which gave the best inhibition effect and it mixed with different concentrations of HE (ZM) until the inhibiting effectiveness achieved its maximum. Indeed, the objective is to recover the $Z$. mays waste which is characterized by a better yield as well as by important polyphenolic content especially flavonoids when compared to the HE (AV) extract [10]. These measurements were carried out under the same conditions as those used for HE extracts alone.

As shown in Figure 1, in the presence of $\mathrm{HE}(\mathrm{AV})$ and $\mathrm{HE}$ (ZM) mixture, both the anodic and cathodic curves shift to lower current densities, accompanied by the emergence of lower values of current densities with the increase of concentration of $\mathrm{HE}(\mathrm{ZM})$, while the concentration of $\mathrm{HE}(\mathrm{AV})$ remains constant at $0.01 \mathrm{gL}^{-1}$. In the use of $\mathrm{HE}(\mathrm{AV}) / \mathrm{HE}$ (ZM) mixture, $E_{\text {corr }}$ gradually shifts to positive direction, which can be ascribed to adsorption of active molecule on the metal surface in acid solution [16]. Therefore, HE (AV)/ $\mathrm{HE}(\mathrm{ZM})$ mixture could be classified as mixed type corrosion inhibitors with cathodic predominant control.

In the cathodic domain, the addition of different concentrations of mixture induces an important decrease of the partial cathodic current corresponding to the reduction of the proton $\mathrm{H}^{+}$. For the anode branch, it is noticed that the current density remains lower than that of the blank for potentials lower than those of the desorption potential $\left(E_{d}\right)$, from which the potential current curves are considerably closer to those of the blank. The sharp increase in current can be related to the marked desorption of the adsorbed inhibitor [17].

The electrochemical parameters of corrosion process are given in Table 1. Meanwhile, based on PP measurements, the inhibiting efficiency is calculated by the following equation:

$$
\eta_{p p} \%=\left(\frac{i_{\text {corr }}-i_{\text {corr } / \mathrm{inh}}}{i_{\text {corr }}}\right) \times 100
$$

where $i_{\text {corr }}$ and $i_{\text {corr/inh }}$ are the corrosion current density values in the presence and absence of the mixture, respectively. 


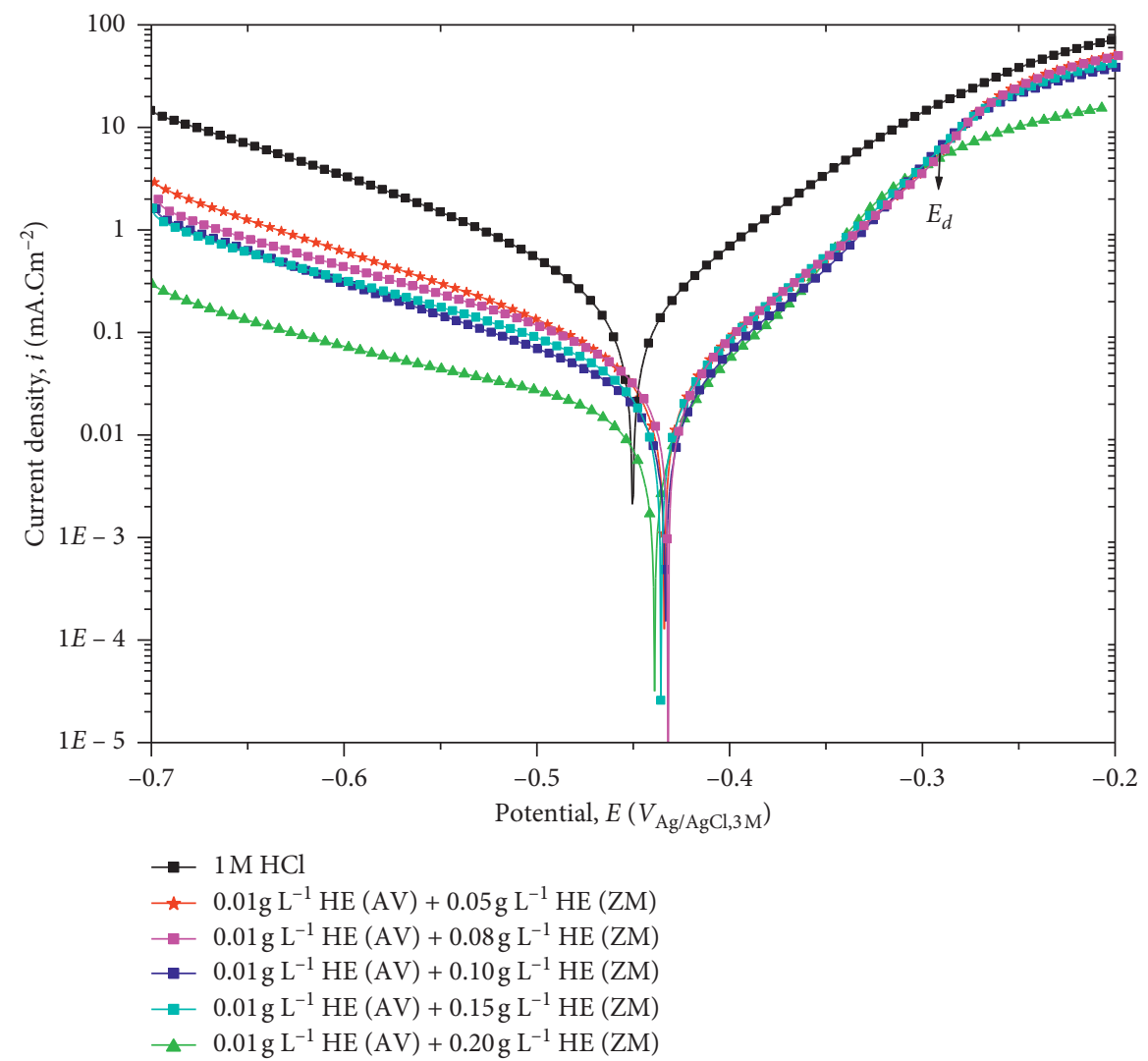

Figure 1: Polarization curves for the mixture of $\mathrm{HE}(\mathrm{AV})+\mathrm{HE}(\mathrm{ZM})$ in $1 \mathrm{M} \mathrm{HCl}$ at $298 \mathrm{~K}$.

TABLE 1: Electrochemical parameters and inhibiting efficiencies obtained from PP measurements for mild steel in $1 \mathrm{M} \mathrm{HCl} \mathrm{solution} \mathrm{with}$ different concentrations of $\mathrm{HE}(\mathrm{AV})+\mathrm{HE}(\mathrm{ZM})$ mixture at $298 \mathrm{~K}$.

\begin{tabular}{|c|c|c|c|c|c|c|}
\hline \multirow[b]{2}{*}{$C_{\text {inh }}\left(\mathrm{gL}^{-1}\right)$} & \multicolumn{4}{|c|}{ Tafel data } & \multicolumn{2}{|c|}{ S\&G data } \\
\hline & $E_{\text {corr }}$ & $i_{\text {corr }}$ & $\left|\beta_{c}\right|$ & $n_{\mathrm{pp}} \%$ & $R_{p}$ & $\mathrm{n}_{\mathrm{S} \& \mathrm{G}} \%$ \\
\hline $1 \mathrm{M} \mathrm{HCl}$ & -416.20 & $337.10 \pm 3.25$ & 147.1 & - & 82 & - \\
\hline $0.01 \mathrm{HE}(\mathrm{AV}) / 0.05 \mathrm{HE}(\mathrm{ZM})$ & -433.79 & $56.17 \pm 2.45$ & 160.1 & 83.33 & 300 & 72.66 \\
\hline $0.01 \mathrm{HE}(\mathrm{AV}) / 0.08 \mathrm{HE}(\mathrm{ZM})$ & -431.78 & $53.66 \pm 2.33$ & 184.4 & 84.08 & 326 & 74.84 \\
\hline $0.01 \mathrm{HE}(\mathrm{AV}) / 0.10 \mathrm{HE}(\mathrm{ZM})$ & -435.54 & $43.11 \pm 2.31$ & 187.8 & 87.21 & 421 & 80.52 \\
\hline $0.01 \mathrm{HE}(\mathrm{AV}) / 0.15 \mathrm{HE}(\mathrm{ZM})$ & -423.75 & $29.82 \pm 1.32$ & 183.8 & 91.15 & 950 & 91.36 \\
\hline $0.01 \mathrm{HE}(\mathrm{AV}) / 0.20 \mathrm{HE}(\mathrm{ZM})$ & -439.35 & $14.24 \pm 1.00$ & 224.4 & 95.77 & 1272 & 93.55 \\
\hline
\end{tabular}

Note: $E_{\text {corr }}$ in $\mathrm{mVAg} / \mathrm{AgCl}, 3 \mathrm{M} \mathrm{KCl}, i_{\text {corr }}$ in $\mu \mathrm{Acm}^{-2},\left|\beta_{c}\right|$ in $\mathrm{mV} \mathrm{dec}{ }^{-1}$, and $R_{p}$ in $\Omega \mathrm{cm}^{2}$.

The inhibition efficiency $\eta_{\mathrm{S} \& \mathrm{G}} \%$ derived from S\&G method is calculated from the polarization resistance, using the following equation:

$$
\eta_{S \& G} \%=\left(\frac{R_{p / \mathrm{inh}}-R_{p}}{R_{p / \mathrm{inh}}}\right) \times 100,
$$

where $R_{p}$ and $R_{p / \text { inh }}$ are the polarization resistance values with and without different concentrations of mixture, respectively.

From Table 1, it is demonstrated that the corrosion of mild steel is inhibited on account of $i_{\text {corr }}$ value decreasing when the mixture is added to the solution. The cathodic reaction process is retarded due to the increase of the cathodic Tafel slopes when different concentration of HE (ZM) is jointly added in the solution.
In this work, only the concentration of $\mathrm{HE}(\mathrm{ZM})$ is changed because the current density registered decreases significantly. In the opposite, when the concentration of HE (AV) is changed, the current densities current does not show any remarkable variation in the density current (not reported here). Besides, the goal is to recycle $\mathrm{ZM}$ waste. In the presence of HE (AV) and HE (ZM) taken separately, the current densities are $49.81 \mu \mathrm{A} \mathrm{cm}^{-2}$ and $82.56 \mu \mathrm{A} \mathrm{cm}^{-2}$, respectively $[10,14]$. However, $i_{\text {corr }}$ decreases significantly with the formulation which means that mild steel corrosion is intensely delayed by these inhibitors' mixture, and a strong synergism inhibitory effect is obtained between HE (AV) and HE (ZM).

The corrosion inhibition effect gradually becomes better when the concentration of HE (ZM) in the mixture increases up to $0.2 \mathrm{~g} \mathrm{~L}^{-1} \mathrm{HE}(\mathrm{ZM})$. The highest $R_{p}$ values of individual 
$\mathrm{HE}(\mathrm{AV})$ and $\mathrm{HE}(\mathrm{ZM})$ are $738.7 \Omega \mathrm{cm}^{2}$ at $0.01 \mathrm{~g} \mathrm{~L}^{-1}[10]$ and $679.00 \Omega \mathrm{cm}^{2}$ at $0.15 \mathrm{~g} \mathrm{~L}^{-1}$ [14], respectively. In the presence of the mixture $\mathrm{HE}(\mathrm{AV}) / \mathrm{HE}(\mathrm{ZM})$, the $R_{p}$ value increases up to $1272 \Omega \mathrm{cm}^{2}$, indicating that the melange improves consequent resistance and acts as good corrosion inhibitor. Similar to the situation of individual inhibitor use, the polarization resistance values of inhibitor mixture increase with the increase of the concentration of $\mathrm{HE}(\mathrm{ZM})$ in the mixture [10]. It should be noted that there is a recorded difference between the two methods (Tafel, S\&G) resulting from the stationary polarization, which intervenes at the level of the different approximations on which each of them is based. Otherwise, the inhibitory efficiencies derived from S\&G method are in the same trend as those obtained by Tafel method.

4.1.2. EIS Measurements. The Nyquist and Bode plots for mild steel in $1 \mathrm{M} \mathrm{HCl}$ at $25^{\circ} \mathrm{C}$ with different concentrations of inhibitors are shown in Figure 2. All Nyquist plots (A, B, and $C$ ) show an increase of loops size with increasing concentration of $\mathrm{HE}(\mathrm{ZM})$ in the mixture $\mathrm{HE}(\mathrm{AV}) / \mathrm{HE}$ (ZM) compared with that in the blank solution, indicating that the mixture slows down remarkably the corrosion process of mild steel. As seen from Figure 2, when the mixtures of $\mathrm{HE}(\mathrm{AV}) / \mathrm{HE}(\mathrm{ZM})$ are added in the solution, the diameters of semicircles become larger than those obtained by $\mathrm{HE}(\mathrm{AV})$ and $\mathrm{HE}(\mathrm{ZM})$ separately $[10,14]$, suggesting that the corrosion process is further inhibited when $\mathrm{HE}(\mathrm{AV})$ is jointly used with HE (ZM) when compared to the separate use of individual inhibitor.

For different mixing concentrations of $\mathrm{HE} \mathrm{(AV)/HE}$ (ZM), there are two separated maximum phases in the Bode diagram (Figure 2(a)). To confirm this hypothesis, we have simulated the experimental diagrams using the simple circuit $\left(R_{s}+\mathrm{CPE}_{d l} / R_{c t}\right.$, Figure 3(a)) and the two-time constant circuit $\left(R_{s}+\mathrm{CPE}_{d l} /\left(R_{c t}+\mathrm{CPE}_{f} / R_{f}\right)\right.$, Figure $\left.3(\mathrm{~b})\right)$.

The Bode diagram (Figure 2(a)) simulated by the simple circuit shows a poor simulation of experimental and simulated spectra, which indicates a second time constant is recently to fit adequately. The first phenomenon at low frequency can also be attributed to the adsorption, and the second phenomenon at mild frequency can be attributed to the charge transfer of inhibitor on the metal surface. For this reason, we have tried several equivalent circuits to obtain inappropriate simulation. Therefore, the circuit $\left(R_{s}+\mathrm{CPE}_{d l} l\right.$ $\left.\left(R_{c t}+\mathrm{CPE}_{f} / R_{f}\right)\right)$ offers a better superposition of the experimental and simulated spectra in the representation of Nyquist (A) and Bode (B) for the mixture. Therefore, the best fitting is obtained by the circuit equivalent to two time constants. The equivalent circuit employed is presented in Figure 3, where $R_{s}$ represents the solution resistance, $R_{c t}$ represents the charge transfer, $R_{f}$ represents the film resistance, and CPE is the constant phase element.

The electrochemical impedance parameters for mild steel in $1 \mathrm{M} \mathrm{HCl}$ in the presence of the formulation $\mathrm{HE}(\mathrm{AV}) / \mathrm{HE}$ (ZM) are obtained by fitting of impedance diagrams by the simple circuit RQ for the blank solution and those with $2 \mathrm{RQ}$ (two time constants) are reported in Table 2. The values of the pseudocapacitances $\left(C_{d l}, C_{f}\right)$ are determined by the two following equations according to $[18,19]$

$$
\begin{aligned}
& C_{d l}=\left(Q_{d l} R_{c t}^{1-n_{d l}}\right)^{1 / n_{d l}}, \\
& C_{f}=\left(Q_{f} R_{f}^{1-n_{f}}\right)^{1 / n_{f}} .
\end{aligned}
$$

The inhibition efficiency is calculated with the following equation:

$$
\eta_{\mathrm{EIS}} \%=\left(\frac{R_{p}-R_{p}^{0}}{R_{p}}\right) \times 100 .
$$

In the absence of the formulation, the polarization resistance corresponds to the charge transfer resistance $\left(R_{p}=R_{c t}\right)$, while in the presence of inhibitors, the value of $R_{p}$ is given by the sum of two contributions: $R_{p}=R_{c t}+R_{f}$ and $R_{p}^{0}$ is the total resistance for blank.

It can be observed from Table 2 that the addition of different concentration of $\mathrm{HE}(\mathrm{ZM})$ in the mixture to the solution causes an increase in $R_{c t}$ and a decrease in $C_{d l}$ which confirms the synergistic inhibition effect between $\mathrm{HE}$ (AV) and $\mathrm{HE}(\mathrm{ZM})$. The highest $\eta_{\text {EIS }} \%$ values of individual $\mathrm{HE}$ (AV) [10] and HE (ZM) [14] are $91.94 \%$ and $93.97 \%$ at 0.01 $\mathrm{gL}^{-1}$ and $0.15 \mathrm{gL}^{-1}$, respectively. However, $\eta_{\mathrm{EIS}} \%$ is $96.53 \%$ for the combination between $0.01 \mathrm{gL}^{-1} \mathrm{HE}(\mathrm{AV})$ and $0.2 \mathrm{gL}^{-1}$ $\mathrm{HE}$ (ZM). Examining the efficiency obtained with the mixture and those using other natural products [20-22], we can conclude that the proposed formulation is very effective for the reason that we get the intense efficiency at low concentrations.

According to the results obtained from EIS and PP methods [10], we have noticed that the inhibiting efficiency obtained by HE (ZM) is due to the presence of flavonoids, especially flavone. Meanwhile, inhibition effect of HE (AV) is due to the presence of condensed tannins, especially catechin. This observation for HE (ZM) and HE (AV) could be attributed to the presence of adsorption centers of oxygen, the heterocyclic oxygen atom, benzyl groups, $\mathrm{O}-\mathrm{H}$, $\mathrm{C}=\mathrm{O}$, and $\mathrm{C}-\mathrm{O}$, and the presence of electron-rich multiple bonds, which meets the effectively responsible for blocking active sites on the metal surface. In addition, when the metal is immersed in the inhibiting solution, the heteroatoms give free, nonbinding electrons for the unoccupied orbits of the metal atom, which ensures strong and stable bonds (coordination bonds) between the inhibitor and the metal surface [23]. Thus, catechin and flavone were capable of forming chelates with metal cations because of the presence of an oxygen atom associated with the heterocyclic as an adsorption site and hydroxyl groups on aromatic rings (Figure 4) [24] which promote surface protection by forming a barrier film on the surface that reduces the diffusion or movement of ions on the metal surface [25].

Meanwhile, when $\mathrm{HE}(\mathrm{AV})+\mathrm{HE}(\mathrm{ZM})$ are mixed, the number of active sites increases and the number of metal complex formations probably increases and therefore the inhibiting efficacy probably increases (Figure 4). 

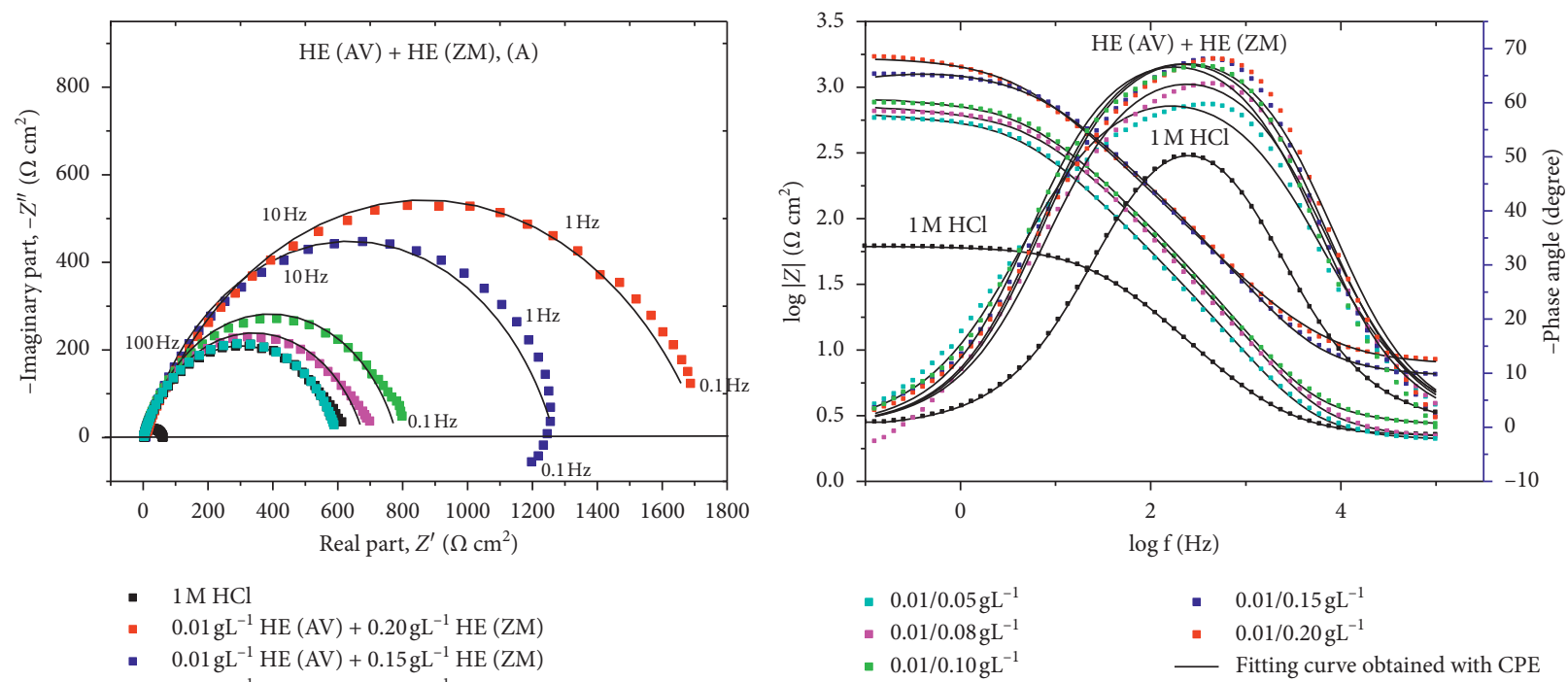

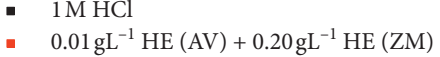

- $0.01 \mathrm{gL}^{-1} \mathrm{HE}(\mathrm{AV})+0.15 \mathrm{gL}^{-1} \mathrm{HE}(\mathrm{ZM})$

- $0.01 \mathrm{gL}^{-1} \mathrm{HE}(\mathrm{AV})+0.10 \mathrm{gL}^{-1} \mathrm{HE}(\mathrm{ZM})$

- $0.01 \mathrm{gL}^{-1} \mathrm{HE}(\mathrm{AV})+0.08 \mathrm{gL}^{-1} \mathrm{HE}(\mathrm{ZM})$

- $0.01 \mathrm{gL}^{-1} \mathrm{HE}(\mathrm{AV})+0.05 \mathrm{gL}^{-1} \mathrm{HE}(\mathrm{ZM})$

_ Fitting curve obtained with $\mathrm{CPE}$

(a)
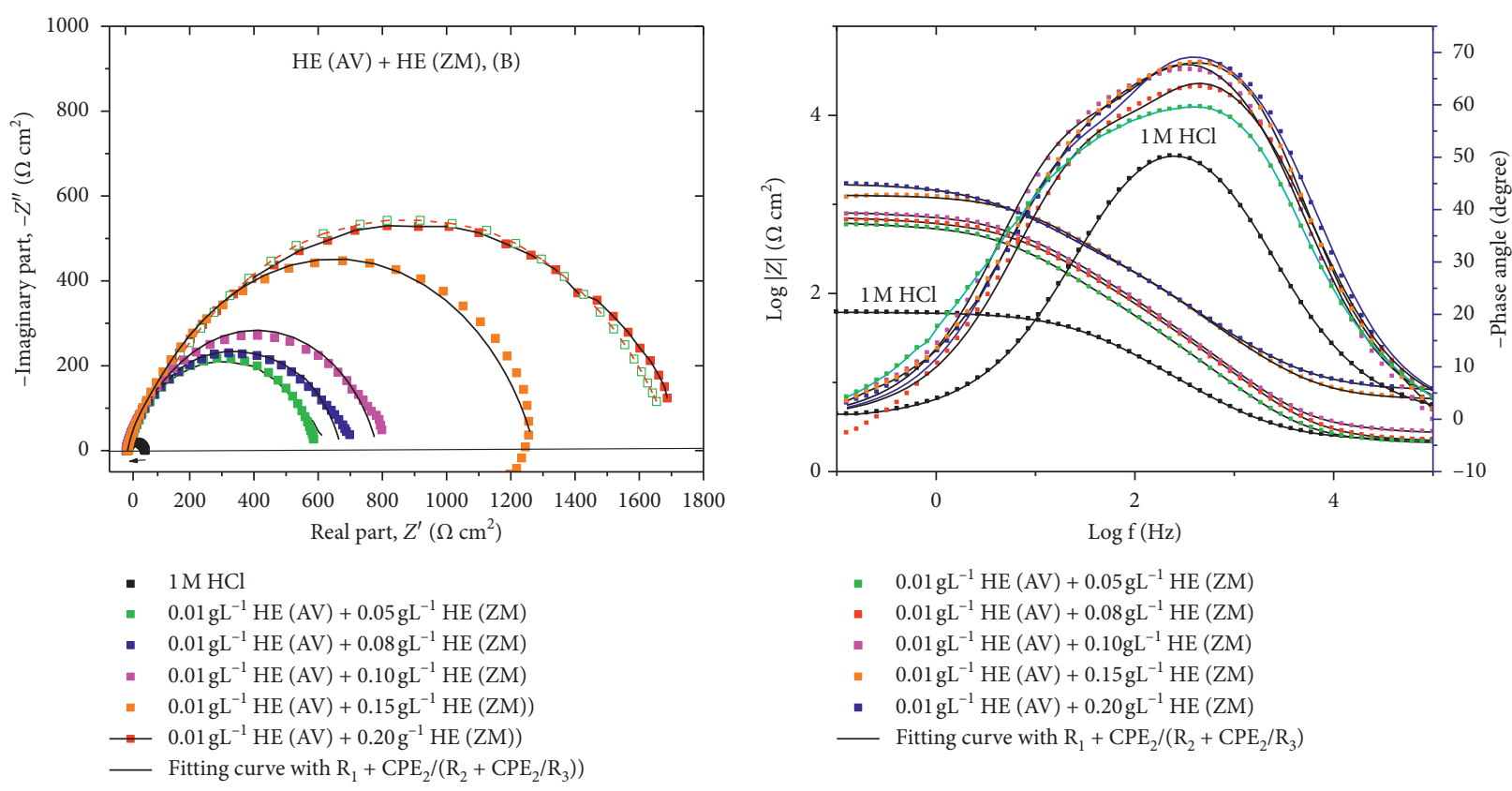

(b)

Figure 2: Nyquist and Bode diagrams of mild steel in $1 \mathrm{M} \mathrm{HCl}$ with and without different concentrations of $\mathrm{HE}(\mathrm{AV}) / \mathrm{HE}(\mathrm{ZM})$ at $298 \mathrm{~K}$ with simulation by $\left(R_{s}+\mathrm{CPE}_{d l} / \mathrm{R}_{c t}\right)$ (a) and $\left(R_{s}+\mathrm{CPE}_{d l} /\left(\mathrm{R}_{c t}+\mathrm{CPE}_{f} / R_{f}\right)\right.$ (b).

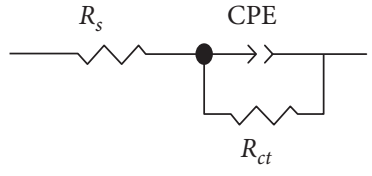

(a)

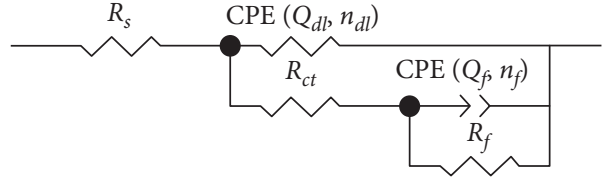

(b)

Figure 3: Equivalent circuit ((a) and (b)) used to fit the impedance data for mild steel in $1 \mathrm{M} \mathrm{HCl}$ with or without $\mathrm{HE}$ (AV)/HE (ZM) mixture. 
TABLE 2: EIS parameters and inhibition efficiencies for mild steel in $1 \mathrm{M} \mathrm{HCl}$ in the presence and absence of different concentrations of HE $(\mathrm{AV}) / \mathrm{HE}(\mathrm{ZM})$ at $298 \mathrm{~K}$.

\begin{tabular}{|c|c|c|c|c|c|c|c|c|c|}
\hline$C_{\mathrm{inh}}\left(\mathrm{gL}^{-1}\right)$ & $R_{s}$ & $R_{c t}$ & $Q_{d l}$ & $C_{d l}$ & $R_{f}$ & $Q_{f}$ & $R_{p}$ & $x^{2}$ & $\eta_{\text {EIS } \%}$ \\
\hline $1 \mathrm{M} \mathrm{HCl}$ & 1.1 & 58.1 & 373.3 & 118.8 & - & - & 59.1 & 0.011 & - \\
\hline $0.01 \mathrm{HE}(\mathrm{AV}) / 0.05 \mathrm{HE}(\mathrm{ZM})$ & 2.1 & 533.4 & 145.1 & 34.8 & 85.3 & 55.2 & 618.7 & 0.022 & 90.44 \\
\hline $0.01 \mathrm{HE}(\mathrm{AV}) / 0.08 \mathrm{HE}(\mathrm{ZM})$ & 2.2 & 598.1 & 137.2 & 27.6 & 109.9 & 45.8 & 708.1 & 0.014 & 91.65 \\
\hline $0.01 \mathrm{HE}(\mathrm{AV}) / 0.10 \mathrm{HE}(\mathrm{ZM})$ & 2.7 & 656.3 & 126.1 & 25.9 & 165.9 & 38.9 & 822.2 & 0.013 & 92.81 \\
\hline $0.01 \mathrm{HE}(\mathrm{AV}) / 0.15 \mathrm{HE}(\mathrm{ZM})$ & 6.2 & 751.5 & 37.3 & 21.6 & 510.4 & 28.6 & 1261.9 & 0.034 & 95.31 \\
\hline $0.01 \mathrm{HE}(\mathrm{AV}) / 0.20 \mathrm{HE}(\mathrm{ZM})$ & 6.5 & 1447 & 27.2 & 19.6 & 325.8 & 26.8 & 1703.4 & 0.004 & 96.53 \\
\hline
\end{tabular}

Note: $R_{f}, R_{c t}$, and $R_{s}$ in $\Omega \mathrm{cm}^{2}, Q_{f}$ and $Q_{d l}$ in $\mu \mathrm{F} S^{n-1} \mathrm{~cm}^{-2}$, and $C_{d l}$ and $C_{f}$ in $\mu \mathrm{F} \mathrm{cm}^{-2}$.

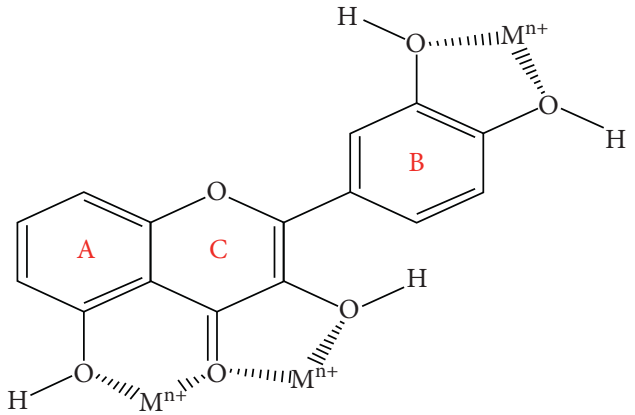

FIgURE 4: Binding sites of flavonoids with the metal.

4.1.3. Comparison between $R_{c t}$ of $H E(A V)+H E(Z M)$ and a Commercial Inhibitor. Dodecylamine $\left(\mathrm{C}_{12} \mathrm{H}_{27} \mathrm{~N}\right)$ is a commercial inhibitor $[26,27]$ that has been extensively studied as a metal inhibitor in corrosive environments. Several studies have focused on the study of dodecylamine alone or mixed with other organic or green compounds as corrosion inhibitor; Zhenyu et al. [22] studied the inhibiting efficiency of dodecylamine against corrosion of carbon steel in an acid medium of $0.3 \mathrm{M} \mathrm{HCl}$. They found that dodecylamine results in a maximum increase in charge transfer resistance to $32.6 \Omega \mathrm{cm}^{2}$ at a concentration of $125 \mathrm{ppm}$ and at temperature of $30^{\circ} \mathrm{C}$ during $30 \mathrm{~min}$ of immersion. Gonzalez [21] studied the synergistic inhibition between dodecylamine and Aloe vera (gel and Acibar) on the corrosion of $1 \mathrm{M}$ $\mathrm{HCl}$ carbon steel. It is discovered that simple dodecylamine inhibits the corrosion of carbon steel, which reaches $1674 \Omega \mathrm{cm}^{2}$ at a concentration of $500 \mathrm{ppm}$ after $15 \mathrm{~h}$ of immersion at $25^{\circ} \mathrm{C}$ with corrosion potential at $1000 \mathrm{tr} \cdot \mathrm{min}^{-1}$. On the other hand, when the immersion time is 2 hours, the resistance reaches $1180 \Omega \mathrm{cm}^{2}$. After the addition of Aloe vera (gel and Acibar) to dodecylamine, the inhibition rate remains almost unchanged compared to the use of dodecylamine alone, which shows that there is no synergy between these compounds. In our study, the mixture provides a strength of $1702 \Omega \mathrm{cm}^{2}$ at a concentration of $0.01 \mathrm{gL}^{-1}(\mathrm{AV}) / 0.2 \mathrm{gL}^{-1} \mathrm{HE}$ (ZM) during $30 \mathrm{~min}$ immersion of the mild steel in $1 \mathrm{M} \mathrm{HCl}$ at a temperature of $25^{\circ} \mathrm{C}$.

4.1.4. Effect of Temperature. The effect of temperature constitutes an important factor in the stability of inhibitive behavior of mixture inhibitor. In the present study, the effect of temperature from 298 to $333 \mathrm{~K}$ is studied at the optimum concentration of $0.01 \mathrm{gL}^{-1} \mathrm{HE}(\mathrm{AV})+0.2 \mathrm{gL}^{-1} \mathrm{HE}(\mathrm{ZM})$ by
EIS. The Nyquist diagrams simulated by the equivalent circuit $\left(R_{s}+\mathrm{CPE}_{d l} /\left(R_{c t}+\mathrm{CPE}_{f} / R_{f}\right)\right)$ in the presence and absence of the mixture at $25^{\circ} \mathrm{C}$ are given in Figure 5 . This circuit allows a perfect fitting between the measurements obtaining experimental and theoretical data. The electrochemical parameters deduced from the impedance spectra are summarized in Table 3. From these results, we note the important diminution of $R_{c t}$ values when the temperature of blank solution increases and enhances the $C_{d l}$ and $Q_{d l}$ values in both uninhibited and inhibited solutions. In the presence of the tested inhibitor, the dissolution of mild steel is extensively retarded. The inhibition efficiencies are found to decrease with increasing the solution temperature from 298 to $333 \mathrm{~K}$. This behavior can be interpreted from the fact that the increase in temperature causes desorption of the inhibitor from the surface of mild steel.

The values of activation energy $E_{a}$ are estimated using Arrhenius equation:

$$
\frac{1}{R_{P}}=A \exp \left(\frac{-E_{a}}{R T}\right),
$$

where $E_{a}$ is the apparent effective activation energy, $R$ is the general gas constant, $T$ is the absolute temperature, and $A$ is the frequency factor.

Since it is known that the corrosion rate is inversely proportional to $R_{c t}$, the values of $\ln \left(1 / R_{p}\right)$ and $\ln \left(R_{p} T\right)^{-1}$ were plotted as a function of 1000/T in Figures 6(a) and 6 for the corrosion mild steel in $1 \mathrm{M} \mathrm{HCl}$ solution in the presence and absence of $0.01 \mathrm{gL}^{-1} \mathrm{HE}(\mathrm{AV}) / 0.2 \mathrm{gL}^{-1} \mathrm{HE}(\mathrm{ZM})$.

The kinetic parameters such as enthalpy and entropy of corrosion process which may also be evaluated from the temperature effect as well as $E_{a}$ are listed in Table 4. An alternative formulation of Arrhenius equation is called transition state, given by the following equation:

$$
\frac{1}{R_{p} T}=\frac{R}{N h} \exp \left(\frac{\Delta S^{*}}{R}\right) \exp \left(\frac{-\Delta H^{*}}{R T}\right),
$$

where $h$ is Planck's constant $\left(h=6.625210^{-34} \mathrm{Js}\right), N$ is Avogadro's number $\left(N=6.023 \cdot 10^{23} \mathrm{~mol}^{-1}\right), \Delta S^{*}$ is the entropy of activation, and $\Delta H^{*}$ is the enthalpy of activation.

From Table 4, we notice that the higher value of activation dissolution energy $E_{a}$ and $A$ factor in presence of inhibitor, when compared to the blank, indicates that strong inhibition action of the mixture is by increasing the energy barrier for the corrosion process, emphasizing the electrostatic character of the inhibitor (physisorption phenomenon) [28]. The 


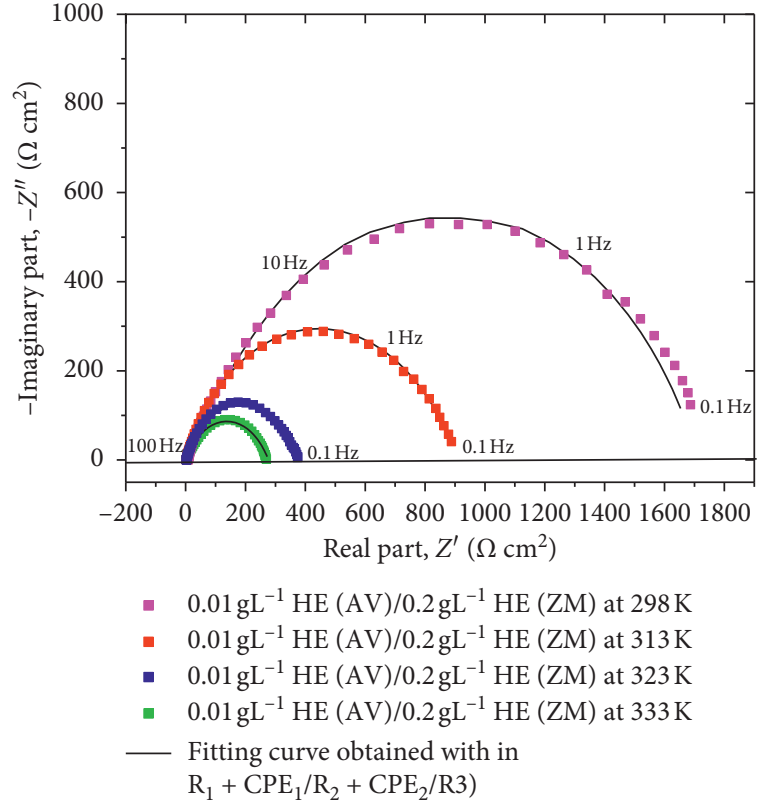

(a)

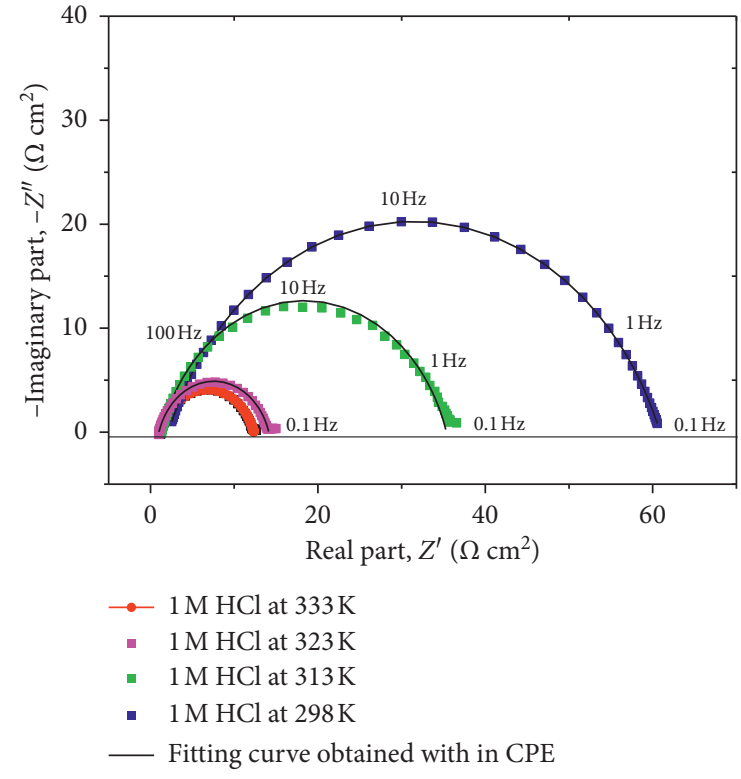

(b)

Figure 5: Nyquist ((a) and (b)) diagrams for mild steel in $1 \mathrm{M} \mathrm{HCl}$ solution at different temperatures in the presence (a) and absence (b) of the mixture $\mathrm{HE}(\mathrm{AV}) / \mathrm{HE}(\mathrm{ZM})$.

TABLE 3: Electrochemical impedance parameters for mild steel in $1 \mathrm{M} \mathrm{HCl}$ in the presence and absence of $0.01 \mathrm{gL}^{-1} \mathrm{HE}(\mathrm{AV}) / 0.2 \mathrm{gL}^{-1} \mathrm{HE}$ $(\mathrm{ZM})$ at different temperatures.

\begin{tabular}{cccccccccc}
\hline \multirow{6}{*}{ Blank } & $T$ & $R_{s}$ & $R_{c t}$ & $Q_{d l}$ & $C_{d l}$ & $R_{f}$ & $Q_{f}$ & $R_{p}$ & $\eta_{\text {EIS }}$ \\
\hline \multirow{6}{*}{ Mixture } & 298 & 1.1 & 58 & 373 & 118.8 & - & - & - \\
& 313 & 1.3 & 34 & 450 & 109.2 & - & - & - \\
& 323 & 1.1 & 13 & 604 & 127.8 & - & - & - \\
& 333 & 1.2 & 11 & 690 & 138.4 & - & - & - \\
& 298 & 6.5 & 1447 & 27 & 19.6 & 325 & 26.8 & 1703 & 96.59 \\
& 313 & 3.1 & 827 & 123 & 29.52 & 81 & 46 & 909 & 96.25 \\
& 323 & 2.6 & 354 & 170 & 30.00 & 29 & 47 & 383 & 84.85 \\
& 333 & 3.4 & 269 & 180 & 34.75 & 15 & 123 & 284 & 79.57 \\
\hline
\end{tabular}

Note: $T$ in $\mathrm{K}, R_{f}, R_{c t}, R_{P}$, and $R_{s}$ in $\Omega \mathrm{cm}^{-2}, Q_{f}$ and $Q_{d l}$ in $\mu \mathrm{F} s^{n-1} \mathrm{~cm}^{-2}$, and $C_{d l}$ in $\mu \mathrm{F} \mathrm{cm}$.

positive sign of the activated enthalpy $\Delta H *$ means that the dissolution phenomenon is of endothermic nature [29]. The entropy of activation $\Delta S^{*}$ in the presence and absence of the inhibitor is largely negative. This indicates that the activated complex in the rate determining step represents an association rather than dissociation step, meaning that a decrease in disordering is taking place ongoing from reactants to the activated complex [30].

4.1.5. Immersion Time. The Nyquist plots simulated by $\left(R_{s}+\mathrm{CPE}_{d l} /\left(R_{c t}+\mathrm{CPE}_{f} / R_{f}\right)\right)$ for mild steel in $1 \mathrm{M} \mathrm{HCl}$ solution in the presence of $0.01 \mathrm{gL}^{-1} \mathrm{HE}(\mathrm{AV}) / 0.2 \mathrm{gL}^{-1} \mathrm{HE}(\mathrm{ZM})$ extract at different immersion times are shown in Figure 7. As seen in the presence of the mixture, the size of the semicircle which gives an indication about the charge transfer resistance of mild steel decreases with exposure time.

Figure 6 indicates that, in the presence of the mixture, the $R_{c t}$ values show exponential decrease with immersion time. Since the $R_{c t}$ value is inversely proportional to corrosion rate, the decrease in $R_{c t}$ values or, in other words, the increase in the corrosion rate may be discussed on the basis that prolonged immersion of mild steel in acid solution allows the cathodic or hydrogen evolution kinetics to increase $[31,32]$.

4.1.6. SEM and EDX Analyses. The image of the mild steel surface by SEM with a resolution of $100 \mu \mathrm{m}$ after 24 hours of immersion in $1 \mathrm{M} \mathrm{HCl}$ alone (Figure 8(a)) shows that the surface of the latter is characterized by the presence of grey spots and some pitting on the surface of the metal, which indicates that the steel is strongly damaged by corrosion almost widespread over the entire surface of the wall in the presence of $1 \mathrm{M} \mathrm{HCl}$. The mild steel immersed in $1 \mathrm{M} \mathrm{HCl}$ with $0.01 \mathrm{HE}(\mathrm{AV}) / 0.2 \mathrm{gL}^{-1} \mathrm{HE}(\mathrm{ZM})$ presents a smooth surface (Figure $8(\mathrm{~b})$ ), indicating that the surface is protected by the formulation of $0.01 \mathrm{HE}(\mathrm{AV}) / 0.2 \mathrm{gL}^{-1} \mathrm{HE}(\mathrm{ZM})$. This 


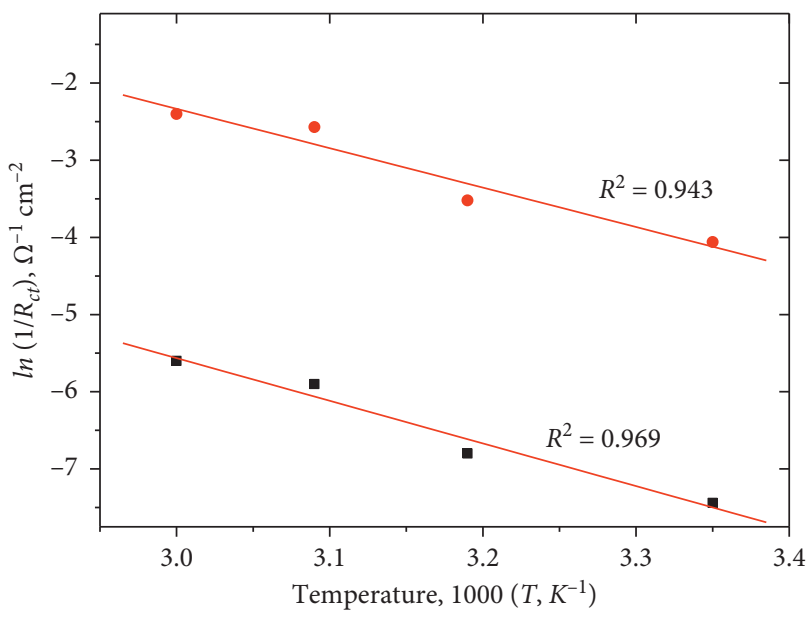

- $0.01 / 0.2 \mathrm{gL}^{-1}$ of $\mathrm{HE}(\mathrm{AV}) / \mathrm{HE}(\mathrm{ZM})$

- $1 \mathrm{M} \mathrm{HCl}$

- Linear fit

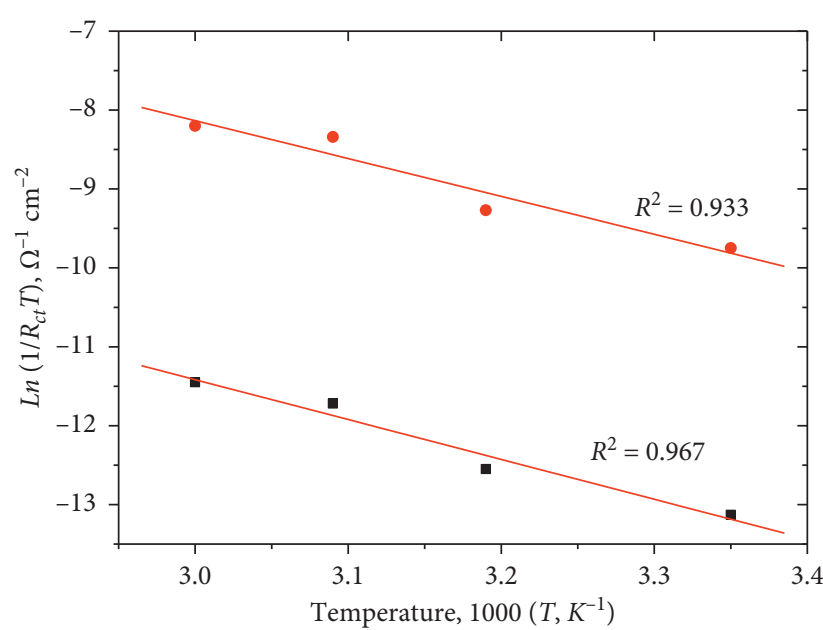

- $0.01 / 0.2 \mathrm{gL}^{-1}$ of $\mathrm{HE}(\mathrm{AV}) / \mathrm{HE}(\mathrm{ZM})$

- $1 \mathrm{M} \mathrm{HCl}$

— Linear fit

(a)

(b)

FIgURE 6: Arrhenius plots of mild steel obtained in $1 \mathrm{M} \mathrm{HCl}$ in the presence and absence of $0.01 \mathrm{HE}(\mathrm{AV}) / 0.2 \mathrm{gL}^{-1} \mathrm{HE}(\mathrm{ZM})$.

TABLE 4: Activation parameters for mild steel in $1 \mathrm{M} \mathrm{HCl}$ with and without $0.01 \mathrm{gL}^{-1} \mathrm{HE}(\mathrm{AV}) / 0.2 \mathrm{gL}^{-1} \mathrm{HE}(\mathrm{ZM})$.

\begin{tabular}{lcccc}
\hline Inhibitor & $A$ & $E_{a}\left(\mathrm{~kJ} \mathrm{~mol}^{-1}\right)$ & $\Delta H *\left(\mathrm{~kJ} \mathrm{~mol}^{-1}\right)$ & $\Delta S *\left(\mathrm{~J} \mathrm{~K} \mathrm{Kol}^{-1}\right)$ \\
\hline Blank & $6.0510^{4}$ & 42.6 & 39.80 & -145.50 \\
Mixture & $4.3410^{5}$ & 45.8 & 31.07 & -239.04 \\
\hline
\end{tabular}

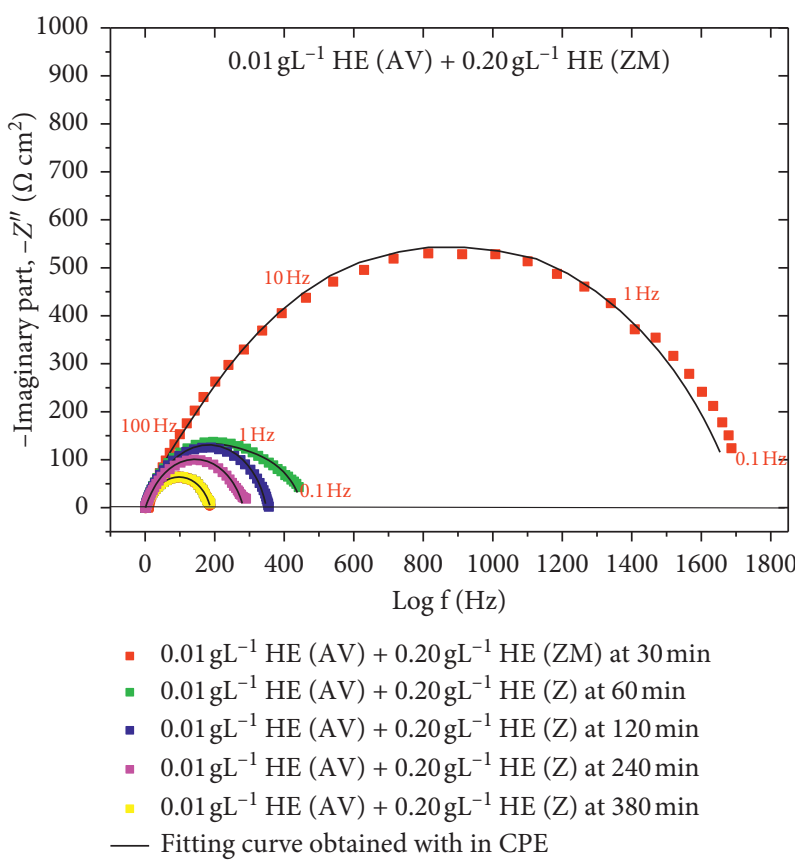

Figure 7: Nyquist plots for mild steel in $1 \mathrm{M} \mathrm{HCl}$ solution containing $\mathrm{HE}(\mathrm{AV}) / \mathrm{HE}(\mathrm{ZM})$ at different immersion times. 


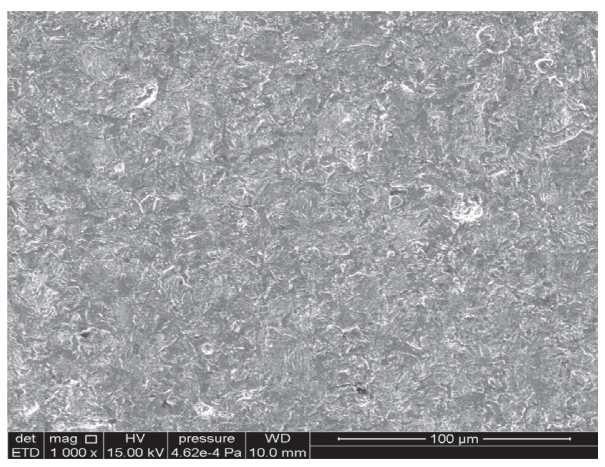

(a)

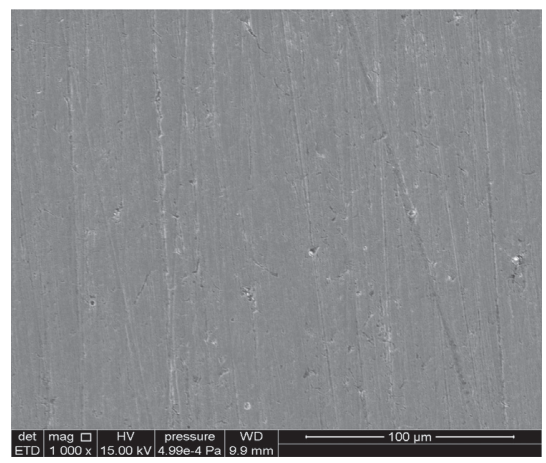

(b)

FIGURE 8: SEM photograph of mild steel: immersed in $1 \mathrm{M} \mathrm{HCl}$ in the absence (a) and presence (b) of $0.01 \mathrm{HE}(\mathrm{AV})+0.2 \mathrm{gL}{ }^{-1} \mathrm{HE}(\mathrm{ZM})$ at $298 \mathrm{~K}$.

observation is probably due to the formation of a good protective film of mixture onto the mild steel surface [33].

\section{Conclusion}

We studied the synergistic effect of the HE (AV)/HE (ZM) mixture on the inhibiting efficiency of mild steel in $1 \mathrm{M} \mathrm{HCl}$ medium. The results found showed that the studied mixture is a good inhibitor of mild steel corrosion, compared to dodecylamine. The thermodynamic parameters showed that the adsorption of the inhibitors follows a physisorption mechanism. Temperature had a negative influence on inhibitory efficiency; in general, an increase in temperature significantly decreased inhibiting efficiency. This can be explained by the fact that the anodic (oxidation of steel components) and cathodic (reduction of protons in acidic environment) processes are thermally activated. The inhibiting efficiency of this mixture decreases with immersion time. The results are confirmed by scanning electron microscopy analysis.

\section{Data Availability}

No data were used to support this study.

\section{Conflicts of Interest}

The authors declare that there are no conflicts of interest.

\section{Acknowledgments}

This work was supported by Laboratory of Engineering, Modeling, and Systems Analysis (LIMAS), Faculty of Sciences, University Sidi Mohamed Ben Abdellah (USMBA), Fez.

\section{References}

[1] C. B. Pradeep Kumar and K. N. Mohana, "Phytochemical screening and corrosion inhibitive behavior of Pterolobium hexapetalum and Celosia argentea plant extracts on mild steel in industrial water medium," Egyptian Journal of Petroleum, vol. 23, no. 2, p. 251, 2014.
[2] H. Ashassi-Sorkhabi, D. Seifzadeh, and M. G. Hosseini, "EN, EIS and polarization studies to evaluate the inhibition effect of 3H-phenothiazin-3-one, 7-dimethylamin on mild steel corrosion in $1 \mathrm{M} \mathrm{HCl}$ solution," Corrosion Science, vol. 50, no. 12, pp. 3363-3370, 2008.

[3] S. A. Ali, M. T. Saeed, and S. U. Rahman, "The isoxazolidines: a new class of corrosion inhibitors of mild steel in acidic medium," Corrosion Science, vol. 45, no. 2, pp. 253-266, 2003.

[4] L. M. Vračar and D. M. Dražić, "Adsorption and corrosion inhibitive properties of some organic molecules on iron electrode in sulfuric acid," Corrosion Science, vol. 44, p. 1669, 2002.

[5] M. Behpour, S. M. Ghoreishi, N. Soltani, and M. SalavatiNiasari, "The inhibitive effect of some bis-N,S-bidentate Schiff bases on corrosion behaviour of 304 stainless steel in hydrochloric acid solution," Corrosion Science, vol. 51, no. 5, pp. 1073-1082, 2009.

[6] Y. Tang, X. Yang, W. Yang, R. Wan, Y. Chen, and X. Yin, “A preliminary investigation of corrosion inhibition of mild steel in $0.5 \mathrm{M} \mathrm{H}_{2} \mathrm{SO}_{4}$ by 2-amino-5-(n-pyridyl)-1,3,4-thiadiazole: polarization, EIS and molecular dynamics simulations," Corrosion Science, vol. 52, no. 5, pp. 1801-1808, 2010.

[7] S. Mo, H. Q. Luo, and N. B. Li, "Plant extracts as "green" corrosion inhibitors for steel in sulphuric acid," Chemical Papers, vol. 70, p. 1131, 2016.

[8] A. Y. El-Etre, "Khillah extract as inhibitor for acid corrosion of SX 316 steel," Applied Surface Science, vol. 252, no. 24, pp. 8521-8525, 2006.

[9] S. Aourabi, M. Driouch, K. Ammor, M. Sfaira, and F. Mahjoubi, "Evaluation of anticorrosion and antioxidant activities of ethanolic extract of Ammi visnaga," Analytical and Bioanalytical Electrochemistry, vol. 10, no. 7, p. 912, 2018.

[10] S. Aourabi, M. D. M. Sfaira, and F. Mahjoubi, "Influence of phenolic compounds on antioxidant and anticorrosion activities of Ammi visnaga extracts obtained ultrasonically in three solvent systems," International Journal of Electrochemical Science, vol. 14, pp. 6376-6393, 2019.

[11] K. O. Orubite and N. C. Ngobiri, "Corn silk as corrosion inhibitor for mild steel in $0.1 \mathrm{M} \mathrm{HCl}$ medium," IOSR Journal of Applied Chemistry, vol. 10, no. 3, pp. 51-60, 2017.

[12] G. Ogbonda, J. Echem, Tubonimi, B. I. G. Lucky, and N. Josephine, "Corrosion inhibition efficiency of mixture of rubber (Hevea brasiliensis) leaf and corn cob (Zea Mays) extracts on mild steel in sulphuric acid solution," Journal of Applied Chemistry, vol. 11, p. 37, 2018. 
[13] X. Li, S. Deng, H. Fu, and X. Xie, "Synergistic inhibition effects of bamboo leaf extract/major components and iodide ion on the corrosion of steel in $\mathrm{H}_{3} \mathrm{PO}_{4}$ solution," Corrosion Science, vol. 78, pp. 29-42, 2014.

[14] S. Aourabi, M. Driouch, M. Kadiri et al., "Valorization of Zea mays hairs waste extracts for antioxidant and anticorrosive activity of mild steel in $1 \mathrm{M} \mathrm{HCl}$ environment," Arabian Journal of Chemistry, vol. 13, no. 9, pp. 7183-7198, 2020.

[15] B. Zerga, B. Hammouti, and M. Sfaira, "Comparative inhibition study of new synthesised pyridazine derivatives towards mild steel corrosion in hydrochloric acid. Part-II: thermodynamic proprieties," International Journal of Electrochemical Science, vol. 7, p. 471, 2012.

[16] S. Aourabi, M. Driouch, M. Sfaira et al., "Phenolic fraction of Ammi visnaga extract as environmentally friendly antioxidant and corrosion inhibitor for mild steel in acidic medium," Journal of Molecular Liquids, vol. 323, Article ID 114950, 2020.

[17] Q. Qu, Z. Hao, L. Li, W. Bai, Y. Liu, and Z. Ding, "Synthesis and evaluation of Tris-hydroxymethyl-(2-hydroxybenzylidenamino)-methane as a corrosion inhibitor for cold rolled steel in hydrochloric acid," Corrosion Science, vol. 51, no. 3, pp. 569-574, 2009.

[18] A. Popova, "Temperature effect on mild steel corrosion in acid media in presence of azoles," Corrosion Science, vol. 49, no. 5, pp. 2144-2158, 2007.

[19] G. J. Brug, A. L. G. van den Eeden, M. Sluyters-Rehbach, and J. H. Sluyters, "The analysis of electrode impedances complicated by the presence of a constant phase element," Journal of Electroanalytical Chemistry and Interfacial Electrochemistry, vol. 176, no. 1-2, pp. 275-295, 1984.

[20] H. Cang, Z. Tang, H. Li, L. Li, J. Shao, and H. Zhang, "Study on the synergistic effect of iodide ion with the extract of artemisia halodendron on the corrosion inhibition," International Journal of Electrochemical Science, vol. 12, Article ID 10484, 2017.

[21] M. H. Gonzalez, “Etude d'un traitement multifonctionnel vert pour la protection contre la corrosion de l'acier au carbone API 5L-X65 en milieu CO2," Thése de Doctorat, Institut National Polytechnique de Toulouse, Toulouse, France, 2011.

[22] C. Zhenyu, H. Ling, Q. Yubing, and G. Xingpeng, "Inhibition effect of dodecylamine on carbon steel corrosion in hydrochloric acid solution," Surface Review and Letters, vol. 19, Article ID 1250060, 2012.

[23] P. B. Raja and M. G. Sethuraman, "Inhibitive effect of black pepper extract on the sulphuric acid corrosion of mild steel," Materials Letters, vol. 62, p. 2977, 2008.

[24] A. Ostovari, S. M. Hoseinieh, M. Peikari, S. R. Shadizadeh, and S. J. Hashemi, "Corrosion inhibition of mild steel in $1 \mathrm{M} \mathrm{HCl}$ solution by henna extract: a comparative study of the inhibition by henna and its constituents (Lawsone, Gallic acid, $\alpha$-d-Glucose and Tannic acid)," Corrosion Science, vol. 51, no. 9, pp. 1935-1949, 2009.

[25] T. Murakawa, S. Nagaura, and N. Hackerman, "Coverage of iron surface by organic compounds and anions in acid solutions," Corrosion Science, vol. 7, no. 2, pp. 79-89, 1967.

[26] E. Gulbrandsen, M. Foss, and J. Sjöblom, "Effect of corrosion inhibitors and oil on carbon dioxide corrosion and wetting of carbon steel with ferrous carbonate deposits," Corrosion Science, vol. 8, Article ID 08343, 2008.

[27] Lu, Y. Qiu, and X. Guo, "Effect of $\mathrm{pH}$ value on the adsorption behavior and inhibition mechanism of dodecylamine on carbon steel," Acta Physico-Chimica Sinica, vol. 24, p. 243, 2008.
[28] B. Zerga, A. Attayibat, M. Sfaira et al., "Effect of some tripodal bipyrazolic compounds on C38 steel corrosion in hydrochloric acid solution," Journal of Applied Electrochemistry, vol. 40, no. 9, pp. 1575-1582, 2010.

[29] M. Beniken, M. Driouch, M. Sfaira, B. Hammouti, M. EbnTouhami, and M. Mohsin, "Kinetic-thermodynamic properties of a polyacrylamide on corrosion inhibition for C-steel in 1.0 M HCl medium: part 2," Journal of Bio- and Tribo-Corrosion, vol. 4, p. 34, 2018.

[30] A. HamdyNour Sh.El-Gendy, "Thermodynamic, adsorption and electrochemical studies for corrosion inhibition of carbon steel by henna extract in acid medium," Egyptian Journal of Petroleum, vol. 22, pp. 17-25, 2013.

[31] E. Khamis and B. A. Abd El-Nabey, "Impedance studies of the effect of time of immersion on the inhibition of the acid corrosion of steel," Corrosion Prevention and Control, vol. 127, 1990.

[32] A. Y. El-Etre, M. Abdallah, and Z. E. El-Tantawy, "Corrosion inhibition of some metals using lawsonia extract," Corrosion Science, vol. 47, p. 385, 2004.

[33] S. Perumal, S. Muthumanickam, A. Elangovan, R. Karthik, R. S. Kannan, and K. K. Mothilal, "Bauhinia tomentosa leaves extract as green corrosion inhibitor for mild steel in $1 \mathrm{M} \mathrm{HCl}$ medium," Journal of Bio- and Tribo-Corrosion, vol. 3, no. 2, 2017. 